\title{
Impact of Ethnic Conflict on the Nutritional Status and Quality of Life of Suburban Villagers in the Solomon Islands
}

\author{
Taro YAMAUCHI ${ }^{1}$, Minato NAKAZAWA ${ }^{2}$, Hiroshi OHMAE ${ }^{3}$, Kiseko KAMEI ${ }^{4}$, \\ Kanae $\mathrm{SATO}^{5}$ and Bernard BAKOTE'E ${ }^{6}$ \\ ${ }^{1}$ Graduate School of Health Sciences, Hokkaido University, Sapporo 060-0812, Japan \\ ${ }^{2}$ Graduate School of Medicine, Gunma University, Maebashi 371-8511, Japan \\ ${ }^{3}$ Department of Parasitology, National Institute of Infectious Diseases, Tokyo 162-8640, Japan \\ ${ }^{4}$ Faculty of Human Care, Teikyo Heisei University, Tokyo 170-8445, Japan \\ ${ }^{5}$ Graduate Course of Nursing and Nutrition, Tenshi College, Sapporo 065-0013, Japan \\ ${ }^{6}$ Solomon Islands Medical Training and Research Institute, Honiara, Solomon Islands
}

(Received June 10, 2009)

\begin{abstract}
Summary This paper describes the health and nutritional status and quality of life (QOL) of suburban villagers in the Solomon Islands 3 y after the 1998-2003 ethnic conflict. Crosssectional data were obtained from a small community located $50 \mathrm{~km}$ east of the capital city ( $n=206,87$ adults and 119 children). A health survey involving urine analysis, anthropometry, and blood pressure measurements was conducted to assess health and nutritional status and child growth. Simultaneously, 57 non-randomly selected adults participated in the QOL questionnaire survey. Results of anthropometry show that participants had good health and nutritional status (mean BMIs: 22.8 and 21.7 for men and women, respectively) and $73 \%$ of boys and $83 \%$ of girls were judged 'normal body size' based on their BMI values. Urinalysis revealed that $88 \%$ of the participants were healthy and indicated that they consumed considerable amounts of purchased food such as rice and tinned meat. These findings suggest that the population's lifestyle had essentially recovered from the ethnic conflict. However, possible consequences of the ethnic conflict on the QOL scores were observed in the environmental domain. This study found a positive association between body fat and QOL. This could be interpreted in terms of the traditionally positive view of large bodies in the South Pacific and as resulting from unstable social conditions prevailing after the ethnic conflict.
\end{abstract}

Key Words body composition, BMI, Melanesia, nutritional status, QOL

The Solomon Islands comprise an independent country consisting of an archipelago of 992 islands to the northeast of Australia. The population of the Solomon Islands, estimated at 533,672 in 2006, is predominantly Melanesian, although there are smaller Polynesian, Micronesian, Chinese, and European communities. Since independence from the United Kingdom in 1978 , the country has experienced great social, environmental, and economic changes. In particular, the process of modernization has accelerated in recent decades with the influence of economic globalization. The GDP per capita was US\$511 in 1986, US\$1,093 in 1996, US\$731 in 2003 (influence of ethnic tension) and US\$923 in 2006 (International Monetary Fund, October 2009) (1).

In December 1998, ethnic tensions between the people of the island of Guadalcanal (where the capital Honiara is situated) and settlers from the neighboring island of Malaita led to violence and a subsequent coup in June 2000 (2). A peace agreement was brokered in October 2000, which largely ended overt manifestations of the ethnic conflict. However, serious problems

E-mail: taroy@med.hokudai.ac.jp persisted, and criminal lawlessness threatened to turn the Solomon Islands into a failed state. The poor security situation and the extortion of government finances led to economic collapse and the erosion of public confidence.

In July 2003, at the request of the Solomon Islands government, the Regional Assistance Mission to Solomon Islands (RAMSI) was deployed; it consisted of police officers, military personnel, and civilians from 15 countries. Since then, the political and economic situation has recovered rapidly. However, many people still suffer from the aftereffects of the ethnic conflict (3). Residents of villages located in the suburbs of Honiara had been experiencing rapid modernization; however, they were temporarily forced to return to subsistence farming and fishing, and their diet changed from purchased food to tubers, fish, and local vegetables because of the ethnic conflict. The ethnic conflict affected not only material but also psychological phenomena. The emotional impact included experiences of life-threatening situations, extreme fear, and extreme shock; these were observed among more than $60 \%$ of adolescents (aged 12-20 y old). Symptoms of post-traumatic stress disorder (PTSD) were evident in more than $70 \%$ of ado- 


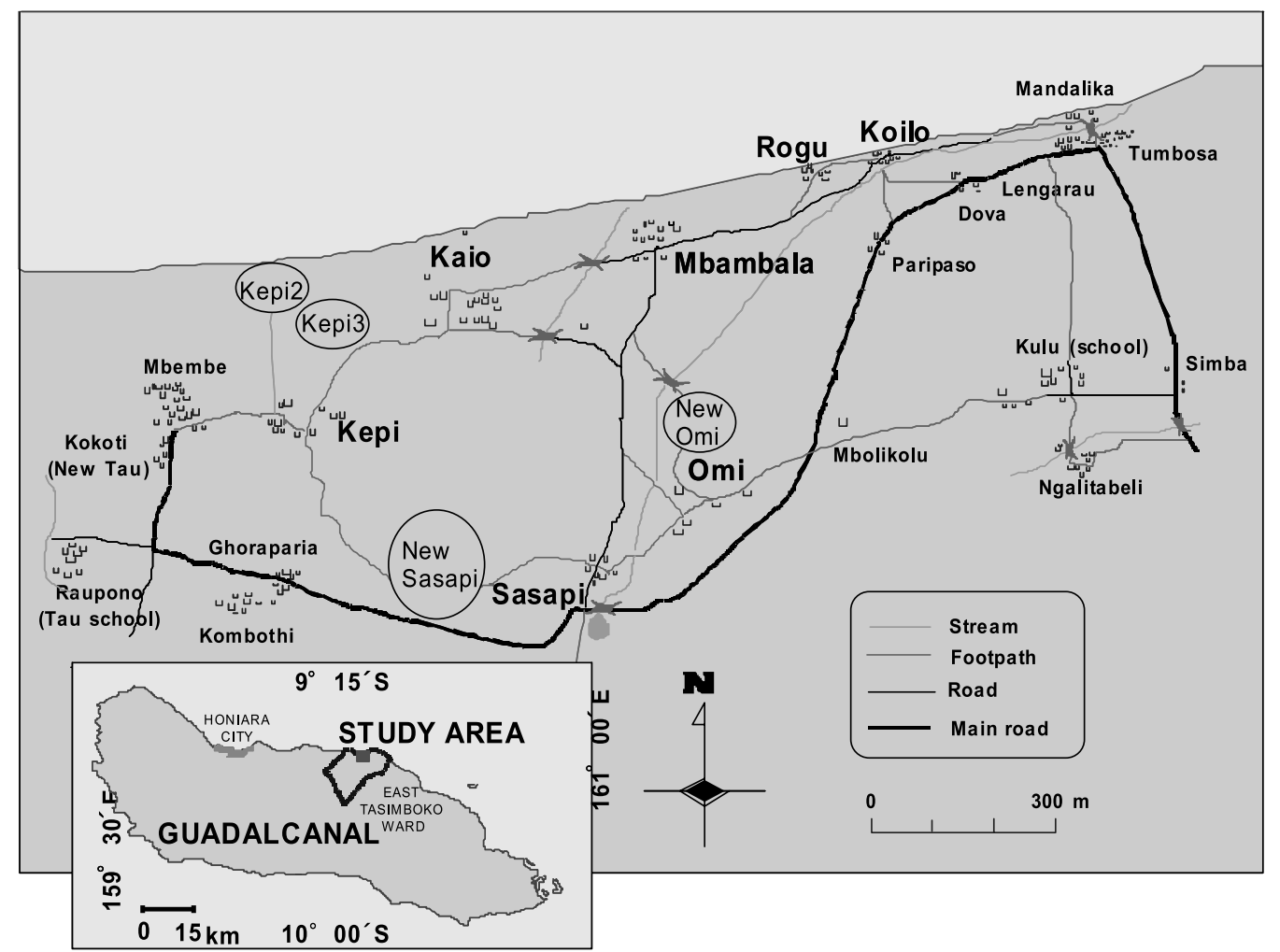

Fig. 1. Study area, located $50 \mathrm{~km}$ east of Honiara, the capital of the Solomon Islands.

lescents in 2006, $3 \mathrm{y}$ after the ethnic conflict had ended (4).

This report describes the health, nutritional status, and quality of life (QOL) of the local population affected by the ethnic conflict, which occurred from 1998 to 2003, 3 y after it had ended (2). The objectives of this study were 1) assess the nutritional status of children and adults living in a suburban village in the Solomon Islands by conducting detailed anthropometric measurements and urine analyses; 2) assess the QOL of the adult population by a structured questionnaire and examine the relationship between QOL scores and indices of the health and nutritional status.

\section{SUBJECTS AND METHODS}

1. Study area and participants. East Tasimboko Ward is located $50 \mathrm{~km}$ east of Honiara, the capital (Fig. 1). This study examined Mbambala, one of the small communities in the eastern half of East Tasimboko Ward. The community consists of seven villages: Mbambala, Kaio, Kepi, Sasapi, Omi, Rogu, and Koilo. According to our census, the de jure population of the area was 290 in September 2006.

The subject population had developed a typical suburban lifestyle involving dietary modernization, commercialization, and movement away from subsistence activities. Before the ethnic conflict, the community had four microbuses to transport villagers to Honiara and three large trucks for transporting agricultural products such as watermelons, sweet potatoes, coconuts, and pineapples to Honiara to sell (5). The villagers raised chickens in the village for both their own consumption and for sale. People frequently went to Honi- ara to purchase imported foods such as noodles, rice, tinned fish, and beer.

However, most daily activities involved agriculture (slash and burn), and most gardens were located within a 1-h walk from the villages. The diet mixed traditional subsistence foods such as tubers (e.g., sweet potatoes, yams, taros, and cassavas), fish, and coconuts, with purchased foods such as noodles, rice, and tinned fish. Details about the Mbambala area are provided elsewhere $(5,6)$. This area was one of the places most affected by the conflict between Guadalcanal and Malaita militants, and $66 \%$ of the population was displaced (2).

In September 2006, 206 villagers living in the Mbambara area (79.2\% of the de jure population), including 87 adults ( $>20 \mathrm{y}$ old, 39 men and 48 women) and 119 children (58 boys and 61 girls), voluntary participated in a health survey involving urine analysis, malaria testing, anthropometry, and blood pressure measurements. Among the 87 adults, 57 (29 men and 28 women) were nonrandomly selected (i.e., to account for imbalances in age, sex, and residential location) to participate in the QOL questionnaire survey. All participants were fully informed about the procedures and purpose of the study, and all gave consent. This study was approved by the Ethics Committee of the Ministry of Health of the Solomon Islands and the Ethics Committee of Epidemiological Studies in the Faculty of Medicine, Gunma University, Japan.

2. Health and nutritional status. Anthropometric dimensions were measured following standard protocols $(7,8)$. Height was measured to the nearest $1 \mathrm{~mm}$ using an anthropometer (GPM, Switzerland), and body 
weight was measured to the nearest $0.1 \mathrm{~kg}$ using a portable digital scale (HD-654, Tanita, Japan). Body mass index (BMI) was calculated from these values. Upper arm, waist, and hip circumferences were measured to the nearest $0.1 \mathrm{~cm}$ using a flexible tape measure, and the waist/hip ratio was calculated. Skinfold thickness was measured to the nearest $0.2 \mathrm{~mm}$ at the triceps and at subscapular sites using skinfold calipers (Holtain, UK). The percentage of body fat (\% fat) was estimated using the predictive equation of Durnin and Womersley (9) in combination with the equation of Siri (10).

Blood pressure was measured for adults using a digital sphygmomanometer (HEM-757, Omron, Japan) with the subjects in a sitting position. The resting heart rate (HR) was measured simultaneously. The averages of two readings each for the systolic (SBP) and diastolic (DBP) blood pressures and HR were used for the analyses. Based on the World Health Organization-International Society of Hypertension (WHO-ISH) guidelines (11), hypertension was defined as $\mathrm{SBP} \geq 140 \mathrm{mmHg}$ or $\mathrm{DBP} \geq 90 \mathrm{mmHg}$.

Participants were asked to collect their early morning first urine. Urine samples were collected in paper disposable cups by the villagers themselves. To avoid degradation of samples, just after the collection, dipsticks (NMultistix SG-L, Siemens Healthcare Diagnostics K.K., Tokyo) were applied to check glucose for diabetes, bilirubin and ketone body for hepatic function, occult blood, protein and urobilinogen for renal function, nitrite and leukocyte status for urinary tract infection, and $\mathrm{pH}$ in relation with diet (12). Recovery rate of urine collection was $92.0 \%$. The positive proportion for other items than $\mathrm{pH}$ and the mean levels of $\mathrm{pH}$ were analyzed.

3. $Q O L$ assessment. Participants completed the short version of the World Health Organization's QOL measurement (WHOQOL-BREF) (13). The WHOQOLBREF was developed from the WHOQOL-100 in response to the need for a briefer instrument to measure QOL (13). The WHOQOL assesses how individuals perceive their position in life in the context of their culture and value systems, and in relation to their goals, expectations, standards, and concerns (14). The instrument emerged from a collaboration among 15 culturally diverse institutions over the course of $4 \mathrm{y}$.

The WHOQOL-BREF is a self-report survey that measures subjective QOL based on two general questions about QOL and satisfaction with health and 24 specific questions assessing four QOL domains: physical (seven items), psychological (six items), social (three items), and environmental (eight items) (Table 1). Not all of the participants understood English, the official language of the Solomon Islands, so the WHOQOL-BREF and additional questions were answered through verbal interviews conducted by a trained local assistant who had a college education and could speak English and the local languages (Pidgin, the lingua franca in the Solomon Islands, and Lengo, the villagers' mother tongue) fluently.

Usually, the QOL scores of the four domains are multiplied by 4 to allow direct comparison with scores
Table 1. WHOOOL-BREF domains and facets.

Domains and facets

1. Physical health
Activities of daily living
Dependence on medicinal substances and medical aids
Energy and fatigue
Mobility
Pain and discomfort
Sleep and rest
Work Capacity
2. Psychological
Bodily image and appearance
Negative feelings
Positive feelings
Self-esteem
Spirituality/Religion/Personal beliefs
Thinking, learning, memory and concentration
3. Social relationships
Personal relationships
Social support
Sexual activity
4. Environment
Financial resources
Freedom, physical safety and security
Health and social care: accessibility and quality
Home environment
Opportunities for acquiring new information and skills
Participation in and opportunities for recreation/
leisure activities
Physical environment (pollution/noise/traffic/climate)
Transport
Overall QOL
General health

derived from the original WHOQOL-100 (13). In this study, however, the simple averaged score for each domain was used for the analyses because we did not intend to compare scores with the WHOQOL-100 but to compare QOL scores of the four domains with health/ nutritional indices (15).

4. Statistical analysis. The data are expressed as the mean \pm SD. Gender differences and the differences in height and weight between 1995 and 2006 were examined using an unpaired $t$-test. Correlations between the QOL scores and health/nutritional indices were tested using Pearson's correlation test. All analyzes were conducted with the JMP statistical package (SAS Institute, Cary, NC, USA); $p<0.05$ was considered significant.

\section{RESULTS}

\section{Health and nutritional status}

Table 2 shows the anthropometry measurements, blood pressure, and resting HR of the adults. Men had significantly higher values than women for body weight, height, arm circumference, and SBP, whereas women had a higher \%fat and skinfold thickness values. No significant gender differences were found for age, BMI, waist and hip circumferences, waist/hip ratio, DBP, or resting heart rate.

Using the WHO criteria (16), the mean BMI values 
Table 2. Anthropometric characteristics of the participants.

\begin{tabular}{|c|c|c|c|c|}
\hline Valuables & & $\begin{array}{c}\text { Women } \\
n=48\end{array}$ & $\begin{array}{c}\text { Men } \\
n=39\end{array}$ & $p$ \\
\hline \multirow[t]{2}{*}{ Age (y) } & Mean & 38.3 & 43.0 & Not significant (NS) \\
\hline & SD & 13.3 & 15.3 & \\
\hline \multirow[t]{2}{*}{ Body weight (kg) } & Mean & 50.7 & 62.1 & $<0.0001$ \\
\hline & SD & 8.5 & 14.2 & \\
\hline \multirow[t]{2}{*}{ Height $(\mathrm{cm})$} & Mean & 152.6 & 164.8 & $<0.0001$ \\
\hline & SD & 5.3 & 5.4 & \\
\hline \multirow[t]{2}{*}{ Body mass index $\left(\mathrm{kg} / \mathrm{m}^{2}\right)$} & Mean & 21.7 & 22.8 & NS \\
\hline & SD & 3.0 & 4.6 & \\
\hline \multirow[t]{2}{*}{ Arm circumference $(\mathrm{cm})$} & Mean & 24.7 & 27.6 & $<0.0001$ \\
\hline & $\mathrm{SD}$ & 2.5 & 3.5 & \\
\hline \multirow[t]{2}{*}{ Waist circumference $(\mathrm{cm})$} & Mean & 81.8 & 80.9 & NS \\
\hline & SD & 8.8 & 12.0 & \\
\hline \multirow[t]{2}{*}{ Hip circumference (cm) } & Mean & 91.2 & 91.2 & NS \\
\hline & SD & 6.1 & 8.4 & \\
\hline \multirow[t]{2}{*}{ Waist-hip ratio } & Mean & 0.9 & 0.9 & NS \\
\hline & SD & 0.1 & 0.1 & \\
\hline \multirow[t]{2}{*}{ Triceps skinfold (mm) } & Mean & 13.4 & 9.0 & $<0.005$ \\
\hline & SD & 5.0 & 7.5 & \\
\hline \multirow[t]{2}{*}{ Subscaplar skinfold (mm) } & Mean & 21.3 & 11.9 & $<0.0001$ \\
\hline & SD & 8.2 & 7.8 & \\
\hline \multirow[t]{2}{*}{ Body fat $(\%)$} & Mean & 29.7 & 16.4 & $<0.0001$ \\
\hline & $\mathrm{SD}$ & 5.9 & 6.7 & \\
\hline \multirow[t]{2}{*}{ Systolic blood pressure (mmHg) } & Mean & 95.0 & 101.0 & $<0.05$ \\
\hline & SD & 10.7 & 11.0 & \\
\hline \multirow[t]{2}{*}{ Diastolic blood pressure (mmHg) } & Mean & 69.7 & 72.5 & NS \\
\hline & $\mathrm{SD}$ & 9.2 & 7.3 & \\
\hline \multirow[t]{2}{*}{ Heart rate (beat/min) } & Mean & 75.6 & 73.7 & NS \\
\hline & SD & 9.9 & 12.9 & \\
\hline
\end{tabular}

were within the normal range $(18.5 \leq \mathrm{BMI}<25.0)$ for both sexes. In fact, individual analyses revealed that 32 men $(82 \%)$ and 37 women $(80 \%)$ were normal weight $(18.5 \leq \mathrm{BMI}<25.0)$. Only two men and three woman were underweight $(\mathrm{BMI}<18.5)$, and five men and six women were overweight (including two men and one woman who were obese, $\mathrm{BMI} \geq 30$.0, in each sex). Based on the definition of hypertension given by the WHO-ISH guidelines ( $\mathrm{SBP} \geq 140 \mathrm{mmHg}$ or $\mathrm{DBP} \geq 90 \mathrm{mmHg}$ ) (11), the mean values of SBP and DBP were within the normal range for both sexes, although one woman (aged $67 \mathrm{y})$ was categorized as hypertensive.

The weights and heights of children of different age groups and sexes are shown in Fig. 2. Four percentile curves for weight (50th, 25th, 10th and 3rd), and five for height (50th, 25th, 10th, 5th and 3rd), taken from US reference data (2000 CDC growth charts) (17) were superimposed on the graphs. The smoothed curves from the Solomon Islands' data (broken lines) correspond to approximately the 3rd percentile of the US reference data for both weight and height in boys, whereas the weight and height in girls approached to 10th percentile in height and greater than 25 th percentile in weight of the US data after $9 \mathrm{y}$ old.

The results of urinalysis are shown in Table 3. No one had a positive result in both glucose and bilirubin. The highest prevalence was leukocytes $(n=13,6.3 \%)$ and prevalence of other items ranged between 1.5 and $2.9 \%$ (Table 3). Almost all of the participants $(n=182,88 \%)$ had negative results in all urine indices. The mean of the urine $\mathrm{pH}$ was 6.05 (95\% CI 5.94 to 6.17).

2. $Q O L$

Table 4 shows the average QOL scores for the physical, psychological, social relationship, and environmental domains and the total average (average of the 26 scores) by gender. The mean score in each domain ranged from 2.94 (environmental domain in men) to 4.17 (social relationship domain in women). No significant gender differences were observed for the four domains or the total average. According to the spider chart in Fig. 3, the pattern of QOL scores by domain (four domains and total average) was identical between men and women.

3. Relationships between $Q O L$ and health/nutritional indices

As no significant gender difference was found in the QOL score for each domain or the total average, the QOL scores of both genders were combined and compared with health/nutritional indices such as body weight, height, BMI, circumference, skinfold thickness, percentage of body fat, blood pressure, and HR. The correlation analyses revealed positive relationships between the QOL scores and indices related to body fat (Table 5). 


\section{Weight}

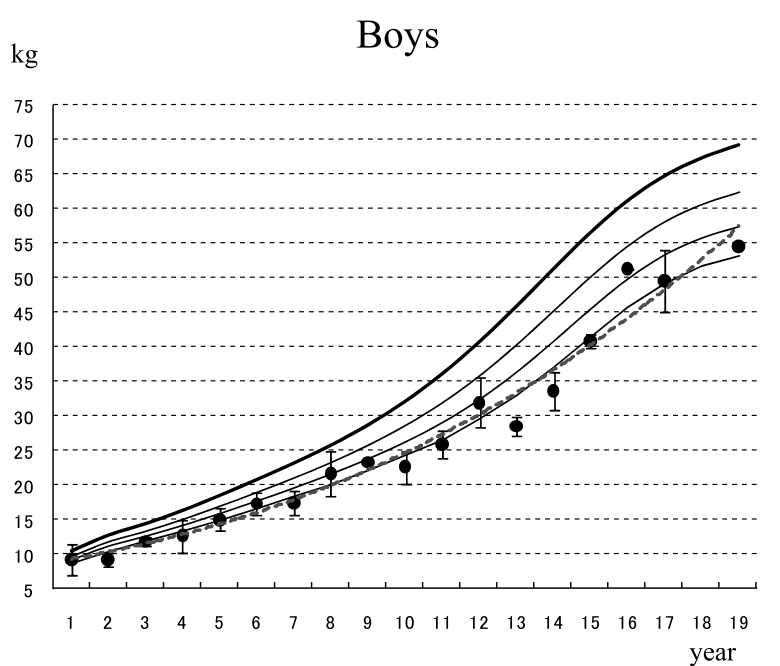

\section{Height}

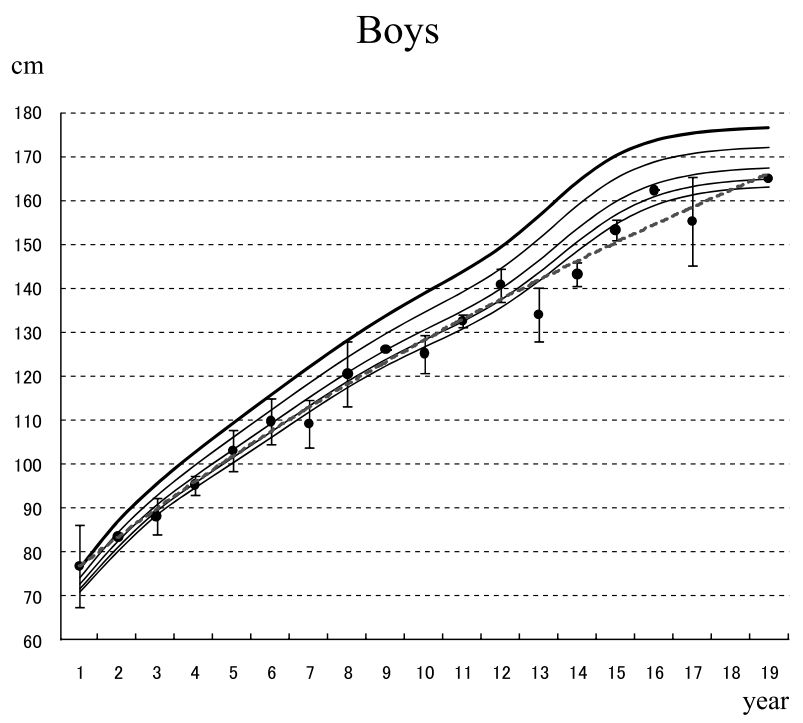

Girls

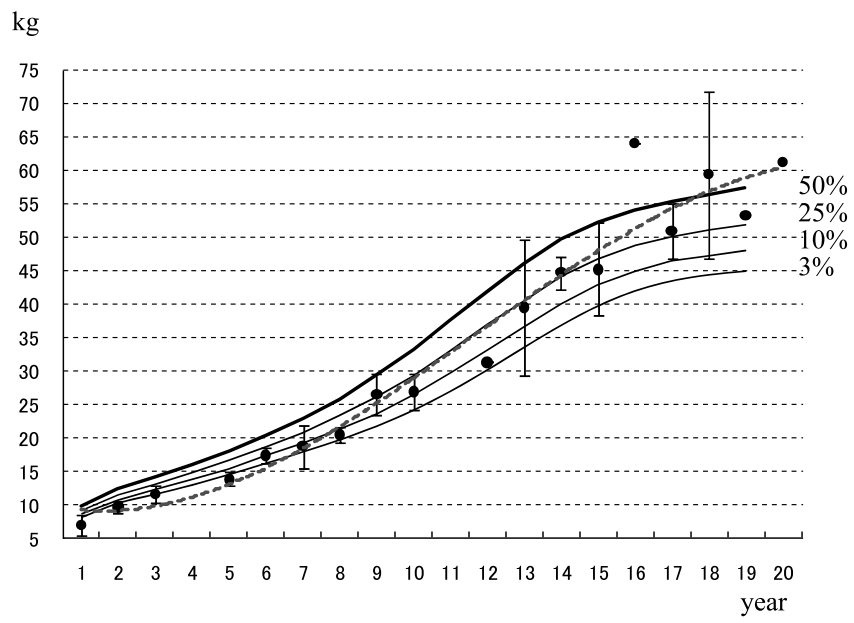

Girls

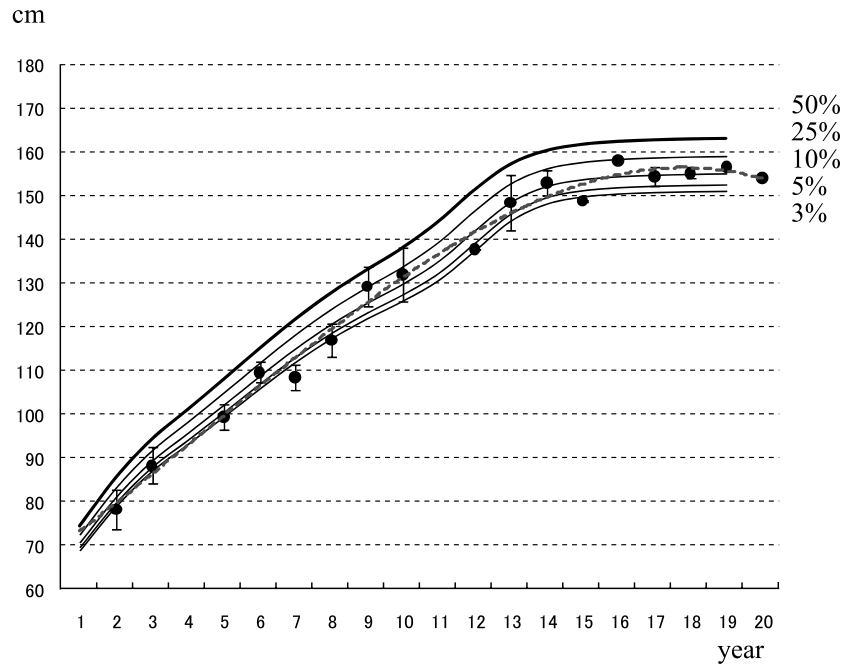

Fig. 2. Growth in weight and height of boys and girls (mean and SD) compared with US reference percentiles: 50th, 25th, 10th, 5th and 3rd.

Table 3. Positive rates for urinalysis screening test.

\begin{tabular}{lrc}
\hline \multirow{2}{*}{ Test item } & \multicolumn{2}{c}{ Positive } \\
\cline { 2 - 3 } & $n$ & $\%$ \\
\hline Urobilinogen & 3 & 1.5 \\
Protein & 4 & 1.9 \\
Occult blood & 6 & 2.9 \\
Ketone body & 2 & 1.0 \\
Glucose & 0 & 0.0 \\
Bilirubin & 0 & 0.0 \\
Leukocyte & 13 & 6.3 \\
Nitrite & 3 & 1.5 \\
pH & & $5.94-6.17$ \\
\hline
\end{tabular}

Table 4. OOL scores by gender and domains.

\begin{tabular}{lccr}
\hline \multicolumn{1}{c}{ Domain } & $\begin{array}{c}\text { Number of } \\
\text { questions }\end{array}$ & $\begin{array}{c}\text { Women } \\
n=28\end{array}$ & $\begin{array}{c}\text { Men } \\
n=29\end{array}$ \\
\hline 1. Physical health & 7 & $3.52 \pm 0.36$ & $3.43 \pm 0.49$ \\
2. Psychological & 6 & $3.69 \pm 0.45$ & $3.67 \pm 0.41$ \\
3. Social relationships & 3 & $4.17 \pm 0.63$ & $3.99 \pm 0.64$ \\
4. Environment & 8 & $2.95 \pm 0.37$ & $2.94 \pm 0.43$ \\
Total average & $26^{1}$ & $3.45 \pm 0.25$ & $3.4 \pm 0.35$ \\
\hline
\end{tabular}

${ }^{1}$ Sum of questions from the four domains and two general questions (see text in detail).

\footnotetext{
${ }^{1}$ Mean and 95\% CI.
} 


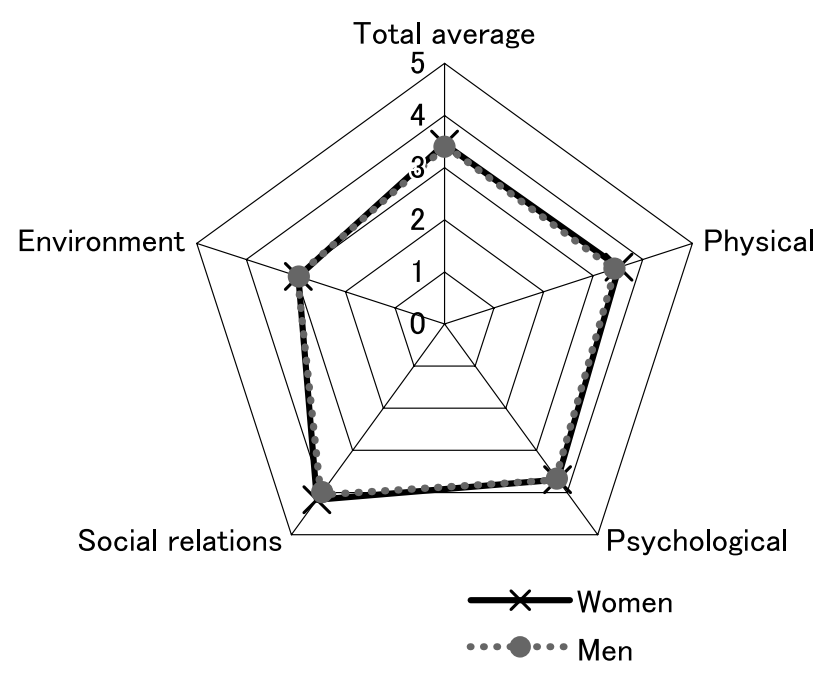

Fig. 3. QOL scores by gender and domains.

\section{DISCUSSION}

1. Impact of ethnic tension on the people and community in 2006

In terms of health and nutritional status, no clear impact of the ethnic conflict was observed in either men or women. BMI values suggested that the men and women were not malnourished but had good nutritional status. The mean percentage of body fat in women approached 30\% (Table 2), suggesting that women tended to be overweight. Based on the BMI cutoff values developed by the International obese task force (IOTF) $(18,19), 73 \%$ of boys and $83 \%$ of girls were categorized 'normal.' All participants, except for one woman older than $60 \mathrm{y}$, were normotensive. The results of urine test showed that $88 \%$ of the participants were negative in all indices.

By contrast, the ethnic conflict had a residual socioeconomic impact on the community. A bridge for the transportation of people and goods (especially purchased food) between the villages and the capital was destroyed during the ethnic conflict and had not been fixed. In addition, the community-owned microbus was burned in the ethnic conflict. Accessibility to the capital city was still poor during the study period (September 2006). Furthermore, villagers were not able to return to their former jobs and instead engaged in semi-subsistence farming and fishing.

Nevertheless, the villagers' lifestyle had recovered rapidly after the ethnic conflict ended in 2003. One good example is the diet. We postulated that during the ethnic conflict (1998-2003), it must have been very difficult for the villagers to access purchased foods such as rice, bread, tinned fish, and noodles that were commonly consumed in 1995 (5). However, simple 24-h recall survey on daily food consumption conducted in 1995 and 2006 revealed that the percentage of villagers who ate rice (as representative of purchased food) at least once a day was almost identical between 1995 (63.3\%, 76 of 120) (5) and $2006(62.7 \%, 32$ of 51 , data not published). The urine $\mathrm{pH}$ level reflects dietary
Table 5. Correlation coefficients between health and nutritional indices and QOL scores.

\begin{tabular}{ll}
\hline \multicolumn{1}{c}{ Domain } & \multicolumn{1}{c}{ Health and nutritional indices } \\
\hline 1. Physical health & $\operatorname{WC}^{1}\left(0.337^{*}\right), \mathrm{W} / \mathrm{H}^{2}\left(0.360^{* *}\right)$, \\
& $\operatorname{TSF}^{3}\left(0.426^{* *}\right), \operatorname{SSF}^{4}\left(0.391^{* *}\right)$, \\
& $\mathrm{FFat}^{5}\left(0.347^{* *}\right), \mathrm{HR}^{6}\left(-0.322^{*}\right)$ \\
2. Psychological & $\operatorname{None}_{\text {3. Social relationships }}$ \\
4. Environment & $\operatorname{TSF}^{7}\left(0.277^{* *}\right)$ \\
Total average & $\operatorname{TSF}\left(0.305^{*}\right)$ \\
& $\operatorname{DBP}\left(0.265^{*}\right), \%$ Fat $\left(0.273^{*}\right)$, \\
\end{tabular}

\footnotetext{
${ }^{1}$ Waist circumference.

${ }^{2}$ Waist-hip ratio.

${ }^{3}$ Triceps skinfold thickness.

${ }^{4}$ Subscaplar skinfold thickness.

${ }^{5}$ Percentage body fat.

${ }^{6}$ Heart rate at sitting position.

${ }^{7}$ Diastolic blood pressure.

${ }^{*} p<0.05,{ }^{* *} p<0.01$.
}

habit. A previous study illustrated significant inter-village difference in urine $\mathrm{pH}$ level among four villages with different dietary patterns in the Solomon Islands (20). The mean urine $\mathrm{pH}$ of this study $(\mathrm{pH}=6.05)$ was identical to the village with the highest consumption on purchased food such as rice and tinned meat (the most acid among the four villages) (20). Therefore, the dietary pattern of the villagers had recovered or was in the final stage of recovery in September 2006.

Further analyses comparing the mean age, height, body weight, and BMI between participants in 1995 ( $n=86,40$ men and 46 women) (5) and those in 2006 ( $n=87,39$ men and 48 women, present study) found no significant difference in any variable for either men or women, supporting the view that the villagers' dietary pattern in 2006 had essentially recovered to the level present before the ethnic conflict.

\section{QOL of a small semi-subsistence population}

The measurement of QOL for valid comparison across cultures is challenging because the equivalence of concepts in QOL scope and content across cultures is debatable (21). The influence of ethnicity on health and health-related QOL is complex and is mediated through biological, demographic, psychosocial, behavioral, and environmental factors $(21,22)$. To overcome these limitations, the WHO developed the WHO-QOL, which makes it possible to conduct collaborative QOL research in different cultural settings and to directly compare the results obtained from these different settings.

Several follow-up studies have used the WHOQOLBREF (23-27). However, most studies evaluated the impact of chronic diseases such as cancer, and only a few have focused on victims of natural disasters and anthropogenic disasters such as wars and conflicts. Tan et al. (28) found that the flooding of Dongting Lake in China had a negative impact on the QOL (WHOQOL Chinese version) of residents in the affected areas, especially farmers, the elderly, and those with introverted 
personalities who had experienced adverse life events. In addition, a study of patients with diabetes in refugee camps in the Gaza Strip (24) found that the QOL scores of these patients were lower in all domains compared to those of controls. The impact of refuge status was more severe in women than in men and in elderly individuals versus younger individuals.

To our knowledge, however, no studies have examined subsistence populations in the South Pacific, making it difficult to compare our findings with those of previous studies. Nevertheless, some interesting findings were derived from the QOL survey. First, the QOL score in each domain and the total score were identical between sexes. Second, among the four domains, the scores for the environmental domain were relatively low, whereas those for the social relationships domain were relatively high in both sexes. Third, contrary to the results typically observed in developed countries, significant positive associations were found between the indices of body fat and QOL scores.

Except for the relatively low score in the environmental domain, no clear effect of the ethnic conflict was observed in the QOL scores. Of the eight facets in the environmental domain, 'transport' was lowest $(2.17 \pm$ 1.20 in men and 2.17 \pm 0.91 in women), followed by 'health and social care' $(2.28 \pm 0.96$ in men and $2.30 \pm 0.88$ in women). The former might reflect the poor accessibility to the city after the ethnic conflict, and the latter might reflect poor health service in the community, as the clinic was damaged in the ethnic conflict and is still not repaired completely.

In view of the relatively high QOL scores observed with regard to social relationships, it would be interesting to investigate the role played by the traditional communal value system, called wantok $(29,30)$, which is widespread in Melanesian societies and still operates in the study area.

In studies in developed countries, negative relationships between the indices of body fat and QOL scores were commonly observed. However, we found a positive relationship between body fat and QOL for the study participants (Table 5). One possible explanation is that large bodies have traditionally held prestige in the South Pacific because they were viewed as representing high status, power, authority, and wealth (31). In addition, those who could afford and obtain purchased food, despite the poor accessibility to the city, might have high QOL scores and might also have a large amount of subcutaneous fat as a result of consuming the purchased food high in protein and fat. Thus, it is reasonable to conclude that those who had relatively large amounts of subcutaneous fat might be people with a high socioeconomic status (SES), who would consequently have a relatively high QOL. Note that the participants were not obese overall (approx. 80\% were normal weight) and that this survey was conducted during an unstable social setting in the post-ethnic-conflict period.

The study has a number of methodological limitations, and the findings should be interpreted accord- ingly. The sample size was relatively small. Data collection was cross-sectional, so comparison of the QOL scores in 2006 with those before the ethnic conflict was impossible. The explanation or translation of the WHOQOL-BREF questionnaire by the local assistant might have caused some bias. Further analyses are needed concerning the reliability and validly of applying the WHOQOL-BREF to a semi-subsistence population in the South Pacific. We accept these limitations but nonetheless believe that our findings contribute to understanding the nutritional status and QOL in suburban areas following ethnic conflicts.

\section{CONCLUSIONS}

In conclusion, the suburban village population in the Solomon Islands had good health and nutritional status rears $3 \mathrm{y}$ after the ethnic conflict had ended. It appears that the lifestyle of the population has essentially recovered or is in the final stage of recovery following the ethnic conflict. An impact of the ethnic conflict on the QOL was observed in the scores in the environmental domain. Simultaneously, the results revealed that the population might share the traditional communal value system peculiar to Melanesian societies. In contrast to previous reports from developed countries, this study found a positive association between body fat and QOL, which might reflect the veneration for larger body sizes in the South Pacific and represent the unstable social conditions after the ethnic conflict.

\section{Acknowledgments}

This research was supported by Grants-in-Aid for Scientific Research (17406018 and 18710208) from the Ministry of Education, Culture, Sports, Science and Technology of Japan. We thank Mr. T. Obara and Ms. K. Kobayashi for collaboration in the field. Finally, we are grateful to the Mbambala villagers for their kindness and participation in this research.

\section{REFERENCES}

1) International Monetary Fund. 2009. World Economic Outlook Databases, October 2009 Edition. [Online]. Available: http://www.imf.org/external/data.htm [accessed June 3, 2009].

2) Fraenkel J. 2004. The Manipulation of Custom: From Uprising to Intervention in the Solomon Islands. Victoria University Press, Wellington.

3) Martiniuk ALC, Millar HC, Malefoasi G, Vergeer P, Garland T, Knight S. 2008. Cooperation, integration, and long-term commitment: What Solomon Islanders and development workers say about health sector aid. Asia Pac J Public Health 20: 287-297.

4) Utsumi T, Nakazawa M, Kawabata M. 2007. The longterm psychological impact of ethnic tension in adolescents of the Solomon Islands. J Int Health 22: 89-94.

5) Nakazawa M, Ohmae H, Leafasia J, Ishii A. 1998. Malaria and its human ecological relations in East Tasimboko, Solomon Islands. In: Malaria Research in the Solomon Islands (Ishii A, Nihei N, Sasa M, eds), p 132-146. Inter Group Corporation, Tokyo.

6) Nakazawa M, Ohmae H, Ishii A, Leafasia J. 1998. Malaria infection and human behavioral factors: A sto- 
chastic model analysis for direct observation data in the Solomon Islands. Am J Hum Biol 10: 781-789.

7) Weiner JS, Lourie JA. 1981. Practical Human Biology. Academic Press, London.

8) Yamauchi T. 2007. Modernization, nutritional adaptability, and health in Papua New Guinean Highlanders and Solomon Islanders. In: Health Change in the AsiaPacific Region (Ohtsuka R, Ulijaszek SJ, eds), p 101126. Cambridge University Press, Cambridge.

9) Durnin JV, Womersley J. 1974. Body fat assessed from total body density and its estimation from skinfold thickness: measurements on 481 men and women aged from 16 to 72 years. Br J Nutr 32: 77-97.

10) Siri WE. 1956. The gross composition of the body. Adv Biol Med Phys 4: 239-280.

11) WHO-ISH Guidelines Subcommittee. 1999. World Health Organization-International Society of Hypertension Guidelines for the Management of Hypertension. J Hypertension 17: 151-183.

12) Remer T, Manz F. 1995. Potential renal acid load of foods and its influence on urine pH. J Am Diet Assoc 95: 791-797.

13) WHOQOL Group. 1998. Development of the World Health Organization WHOQOL-BREF Quality of Life Assessment. Psychol Med 28: 551-558.

14) WHOQOL Group. 1995. The World Health Organization Quality of Life Assessment (WHOQOL): position paper from the World Health Organization. Soc Sci Med 41: 1403-1409.

15) Yamauchi T, Midorikawa T, Hagihara J, Sasaki K. 2007. Quality of life, nutritional status, physical activity, and their interrelationships of elderly living on an underpopulated island in Japan. Geriatr Gerontol Int 7: 26-33.

16) WHO. 2000. Obesity: Preventing and Managing the Global Epidemic. Technical Report Series 894. World Health Organization, Geneva.

17) Kuczmarski RJ, Ogden CL, Guo SS, Grummer-Strawn LM, Flegal KM, Mei Z, Wei R, Curtin LR, Roche AF, Johnson CL. 2002. 2000 CDC growth charts for the United States: methods and development. Vital Health Stat 11 246: 1-190.

18) Cole TJ, Mary CB, Katherine MF, William HD. 2000. Establishing a standard definition for child overweight and obesity worldwide: international survey. $\mathrm{Br} \mathrm{Med} J$ 320: $1240-1243$.

19) Cole TJ, Katherine MF, Dasha N, Alan AJ. 2007. Body mass index cut offs to define thinness in children and adolescents: international survey. $\mathrm{Br}$ Med J 335: 194206.

20) Nakazawa M, Yamauchi T, Tanaka M, Ishimori D, Furusawa T, Midorikawa T, OhtsukaR. 2002. Community health assessment by urine dipstick screening in relation to the variety of lifestyles in the Solomon Islands. People Culture Oceania 18: 35-44.

21) Schmidt S, Bullinger M. 2003. Current issues in crosscultural quality of life instrument development. Arc Phys Med Rehabil 84: S29-S34.

22) Anderson NB, Armstead CA. 1995. Towards understanding the association of socioeconomic status and health: A new challenge for the biophysical approach. Psychosomatic Med 57: 213-225.

23) Ng TP, Lim LC, Jin A, Shinfuku N. 2005. Ethnic differences in quality of life in adolescents among Chinese, Malay and Indians in Singapore. Qual Life Res 14: 1755-1768.

24) Eljedi A, Mikolajczyk RT, Kraemer A, Laaser U. 2006. Health-related quality of life in diabetic patients and controls without diabetes in refugee camps in the Gaza strip: a cross-sectional study. BMC Public Health 6: 268.

25) Izutsu T, Tsutsumi A, Islam A, Matsuo Y, Yamada HS, Kurita H, Wakai S. 2005. Validity and reliability of the Bangla version of WHOQOL-BREF on an adolescent population in Bangladesh. Qual Life Res 14: 17831789.

26) Naumann VJ, Byrne GJ. 2004. WHOQOL-BREF as a measure of quality of life in older patients with depression. Int Psychogeriatrics 16: 159-173.

27) Tsutsumi A, Izutsu T, Kato S, Islam MA, Yamada HS, Kato H, Wakai S. 2006. Reliability and validity of the Bangla version of WHOQOL-BREF in an adult population in Dhaka, Bangladesh. Psych Clin Neurosci 60: 493-498.

28) Tan HZ, Luo YJ, Wen SW, Liu AZ, Li SQ, Yang TB, Sun ZQ. 2004. The effect of a disastrous flood on the quality of life in Dongting lake area in China. Asia Pac J Public Health 16: 126-132.

29) MacDonald M. 1995. Melanesian Communities: Past and Present, 5th ed. Melanesian Institute, Goroka.

30) Whiteman DL. 1995. Melanesia: Its people and cultures. In: Introduction to Melanesian Cultures (Whiteman DL, ed), p 85-104. Melanesian Institute, Goroka.

31) Swami V, Knight D, Tovée MJ, Davies P, Furnham A. 2007. Preferences for female body size in Britain and the South Pacific. Body Image 4: 219-223. 